MNHMT2009-18517

\title{
SURFACE ACOUSTIC WAVES: A NEW PARADIGM FOR DRIVING ULTRAFAST BIOMICROFLUIDICS
}

\author{
Leslie Y. Yeo* \\ James R. Friend \\ Micro/Nanophysics Research Laboratory \\ Department of Mechanical and Aerospace Engineering \\ Monash University \\ Clayton, VIC 3800, Australia \\ Email: leslie.yeo@eng.monash.edu.au
}

\begin{abstract}
Surface acoustic waves (SAWs), which are $10 \mathrm{MHz}$ order surface waves roughly $10 \mathrm{~nm}$ in amplitude propagating on the surface of a piezoelectric substrate, can offer a powerful method for driving fast microfluidic actuation and microparticle or biomolecule manipulation. We demonstrate that sessile drops can be linearly translated on planar substrates or fluid can be pumped through microchannels at typically one to two orders of magnitude faster than that achievable through current microfluidic technologies. Micromixing can be induced in the same microchannel in which fluid is pumped using the SAW simply by changing the SAW frequency to superimpose a chaotic oscillatory flow onto the uniform through flow. Strong inertial microcentrifugation for micromixing and particle concentration or separation can also be induced via symmetry-breaking. At low SAW amplitudes below that at which flow commences, the transverse standing wave that arises across the microchannel afford particle aggregation and hence sorting on nodal lines. Other microfluidic manipulations are also possible with the SAW. For example, capillary waves excited on a sessile drop by the SAW can be exploited for microparticle or nanoparticle collection and sorting. At higher amplitudes, the large substrate accelerations drives rapid destabilization of the drop interface giving rise to inertial liquid jets or atomization to produce 1-10 um monodispersed aerosol droplets. These have significant im-
\end{abstract}

*Address all correspondence to this author. plications for microfluidic chip mass spectrometry interfacing or pulmonary drug delivery. The atomization also provides a convenient means for the synthesis of 150-200 nm polymer or protein particles or to encapsulate proteins, peptides and other therapeutic molecules within biodegradable polymeric shells for controlled release drug delivery. The atomization of thin films containing polymer solutions, in addition, gives produces a unique regular, long-range spatial polymer spot patterning effect whose size and spacing are dependent on the SAW frequency, thus offering a simple and powerful method for surface patterning without requiring physical or chemical templating.

\section{INTRODUCTION}

Surface acoustic waves are $10 \mathrm{~nm}$ order amplitude elastic waves that propagate along the surface of a piezoelectric substrate. The SAW devices here predominantly consist of a double port interdigitated transducer (IDT) with several aluminum electrode finger pairs sputter-deposited onto a single crystal $127.68^{\circ}$ $y x$-cut lithium niobate $\left(\mathrm{LiNbO}_{3}\right)$ piezoelectric crystal substrate By applying an oscillating electrical signal to the IDT using a RF signal generator and power amplifier, a SAW can be generated, which propagates across the substrate as a Rayleigh wave with a wavelength $\lambda$ that correlates with the IDT finger width and spacing; specifically, the finger width and spacing are both $\lambda / 4$. The corresponding SAW resonant frequency is then $f=c_{s} / \lambda$, where $c_{s} \approx 3965 \mathrm{~m} / \mathrm{s}$ is the speed of the SAW in the substrate. 


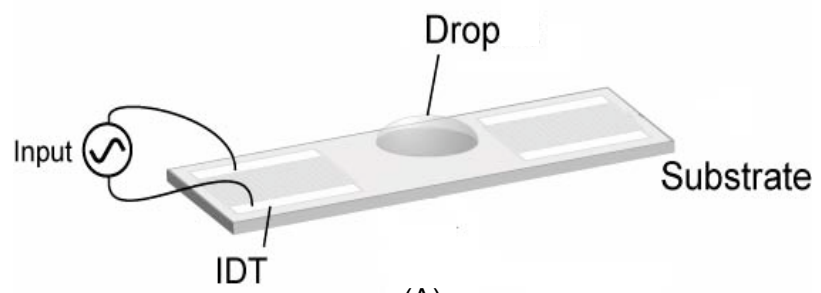

(A)

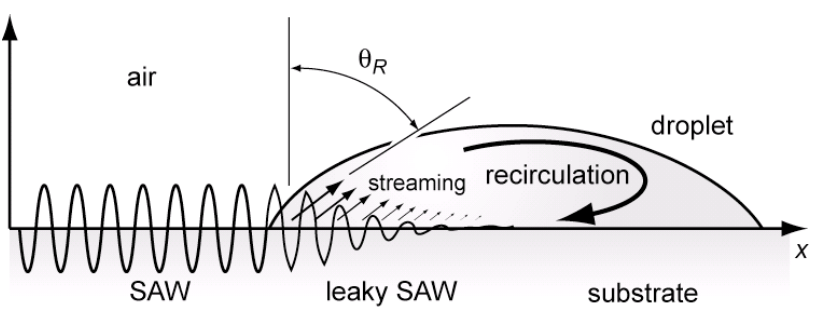

(B)

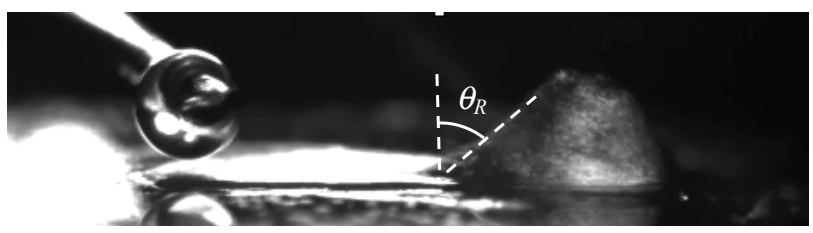

(C)

Figure 1. (A) THE FLUID-STRUCTURAL INTERACTION BETWEEN THE SURFACE ACOUSTIC WAVE AND A DROP IN ITS PROPAGATION PATHWAY CAUSES (B) THE SAW ENERGY TO LEAK INTO THE DROP AT THE RAYLEIGH ANGLE $\theta_{R}$, GIVING RISE TO BULK LIQUID RECIRCULATION (ACOUSTIC STREAMING) IN THE DROP AND A BODY FORCE ACTING ON THE DROP, WHICH, IN TURN, (C) CAUSES THE DROP TO DEFORM INTO AN AXISYMMETRICAL CONICAL SHAPE AND SUBSEQUENTLY TO TRANSLATE ACROSS THE SUBSTRATE.

The origins of SAW microfluidics lies in the fluid-structural coupling that arises when the SAW comes into contact with the fluid. At the leading edge of the drop shown in Fig. 1(A), the SAW diffracts into the drop due to the marked difference between the sound velocity in the substrate $c_{s}$ and that in the fluid, $c_{l}$ ( $\approx 1485 \mathrm{~m} / \mathrm{s}$ for water). This leakage of acoustic energy into the fluid occurs at a specific angle given by the ratio between the sound velocities, known as the Rayleigh angle $\theta_{R}=\sin ^{-1}\left(c_{l} / c_{s}\right) \approx 22^{\circ}$ (Fig. 1(B)), and provides a mechanism for energy transfer into the drop, which gives rise to a longitudinal pressure wave front that drives bulk fluid recirculation within the drop, or acoustic streaming. The horizontal component of the energy transfer into the drop at the Rayleigh angle also results in a body force that acts on the entire drop in the direction of propagation of the SAW, causing the drop to deform into an asymmetrical conical structure along an axis defined the Rayleigh angle (Fig. 1(C)), and eventually to translate in the direction of the SAW propagation.

Figure 2 shows how the drop responds to the SAW in the or-

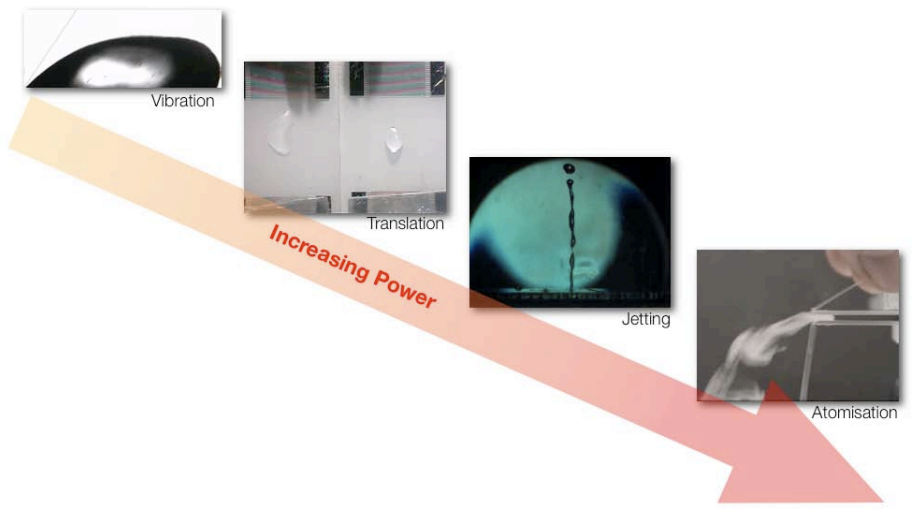

Figure 2. TYPICAL MICROSCALE FLUID MANIPULATIONS THAT CAN BE GENERATED USING THE SURFACE ACOUSTIC WAVE. IN THE ORDER OF INCREASING RF POWER APPLIED TO THE IDT: THE DROP VIBRATES, TRANSLATES (THE LEFT SHOWS A DROP TRANSLATING ON A BARE HYDROPHILIC LITHIUM NIOBATE SUBSTRATE AND THE RIGHT SHOWS THE DROP TRANSLATING ON A SUBSTRATE COATED WITH A HYDROPHOBIC LAYER), FORMS A LONG SLENDER JET, AND, EVENTUALLY ATOMIZES.

der of increasing substrate vibration amplitude as the input power to the IDT is increased [1]. At low powers, the drop deforms into the axisymmetrical conical shape shown and vibrates-the capillary wave vibration, albeit at low amplitudes, has implications for particle assembly and sorting on the free surface. With an increase in the power, the body force on the drop overcomes the contact line pinning force, and the drop begins to translate, thus allowing the SAW to be exploited for moving and manipulating drops in open microfluidic circuits. If the SAW energy is concentrated in the drop, a unique jetting phenomenon occurs, or, if the vibration energy is sufficiently large to overwhelm the capillary stresses holding the drop together, atomization of the entire drop ensues. Below, we discuss each of these phenomena, as well as other manipulations, and their potential for application in practical microfluidic systems.

\section{DROP VIBRATION \& PARTICLE ASSEMBLY}

A sessile drop containing a suspension of $500 \mathrm{~nm}$ particles subject to low amplitude SAW vibration gives rise to a unique particle assembly phenomenon [2]. Figure 3 shows the different particle assembly patterns that arise on the free surface of the drop. Initially, the colloidal particles assemble into linear concentric rings coinciding with the nodal lines of the low amplitude $20 \mathrm{MHz}$ standing wave vibrations induced on the free surface, as shown by the fingerprint-like patterns in Regime A. As the SAW vibration is increased, the colloidal particles in the linear ringlike assemblies are observed to cluster to form pointwise colloidal islands as depicted by the patterns in Regime B. This regime is associated with large amplitude $1 \mathrm{kHz}$ order vibrations associated with the capillary-viscous resonance of the drop. The colloidal 


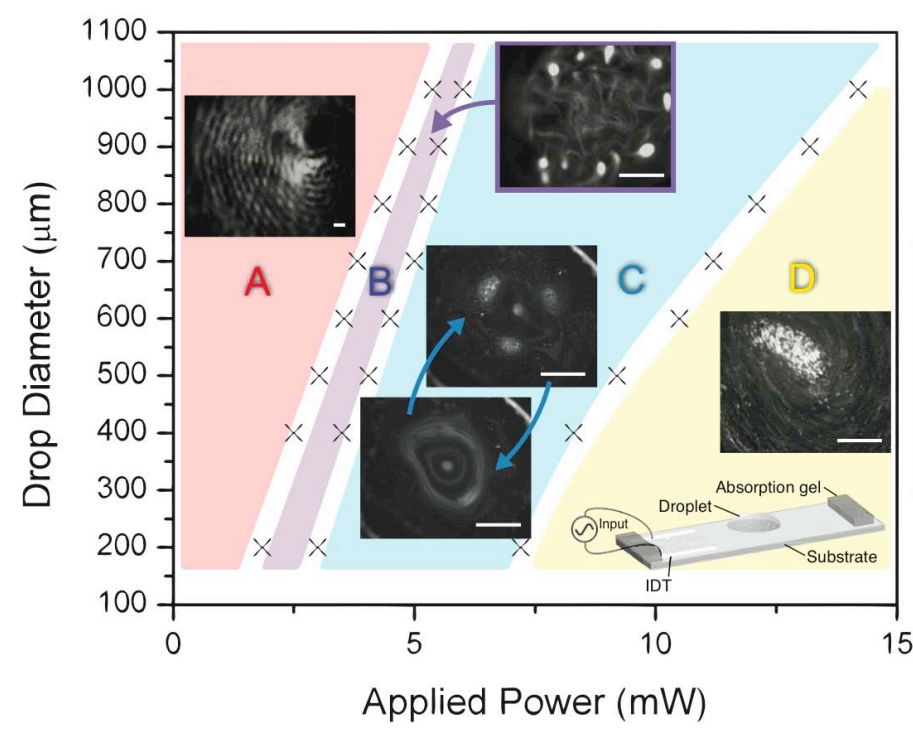

Figure 3. INTERFACIAL COLLOIDAL PATTERNS AS A FUNCTION OF THE INITIAL DROP DIAMETER AND INPUT POWER INDUCED BY LOW POWER SURFACE ACOUSTIC WAVE VIBRATION [2]. THE SCALE BARS IN THE IMAGE INDICATE A LENGTH SCALE OF $200 \mathrm{MI-}$ CRON.

islands therefore appear to form at the intersection between the nodal lines of the low amplitude $20 \mathrm{MHz}$ standing wave vibration and the circular nodal ring of the large amplitude $1 \mathrm{kHz}$ capillaryviscous vibration of the drop. Further increases in the SAW vibration amplitude leads to the onset of significant fluid streaming within the drop which disperses the particles and hence erases the colloidal island assemblies (Regime C). The streaming, however, only lasts for a short transient before ceasing, at which point the colloidal islands are observed to reform until the streaming recommences and erases them again. This cyclic phenomenon occurs aperiodically and the direction of the streaming (clockwise and anticlockwise) is noted to be reasonably random, suggesting that this regime is a transient metastable state and that the commencement and cessation of the streaming is triggered by a peculiar instability arising from the highly nonlinear coupling between the acoustic, hydrodynamic and capillary forces. With further increases in the SAW vibration, however, the streaming becomes stronger and more consistent, leading to permanent dispersion of the particles (Regime D).

\section{DROP TRANSLATION \& MICROCHANNEL PUMPING}

If the SAW vibration amplitude is sufficiently large such that the body force imparted by the leakage of the SAW irradiation on a sessile drop sitting on the substrate overcomes the surface forces that pin the contact line of the drop, the drop can be linearly translated at speeds typically around $1-10 \mathrm{~cm} / \mathrm{s}[3,4]$, which are one to two orders of magnitude larger than the speeds

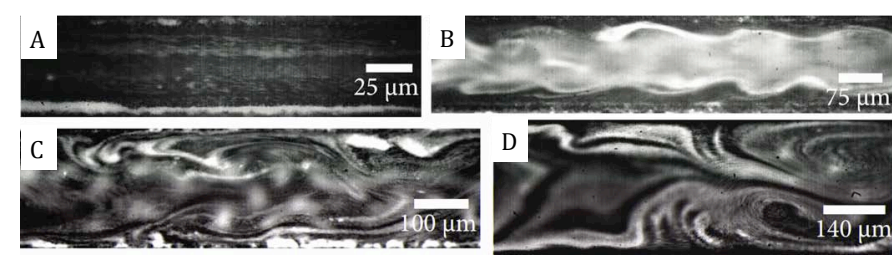

Figure 4. FLOW CONFIGURATION AS A FUNCTION OF THE MICROCHANNEL WIDTH $W$ FOR A FIXED OPERATING FREQUENCY. AS $W$ IS INCREASED, THE UNIFORM THROUGH FLOW IN (A) IS PROGRESSIVELY REPLACED BY AN OSCILLATORY CHAOTIC FLOW AS SEEN IN (B)-(D) [11].

that can be achieved through other actuation schemes, for example, electrowetting [5]. This drop translation capability has been employed for various biological applications, e.g., transport of DNA in discrete droplets for polymerase chain reaction [6] rapid bioparticle collection and concentration for biosensing ap plications [4] and efficient seeding of cells into bioscaffolds fo tissue and orthopedic engineering [7,8]. Due to the high frequency associated with the SAW, the cells are not observed to be denatured; their differentiation and proliferation capabilites also appear to remain intact [9].

In addition, the SAW can be used to pump liquid through microchannels $[10,11]$. As with the SAW-driven drop transport, the micropumping velocities achieved are extremely high, on the order $1 \mathrm{~cm} / \mathrm{s}$, which is one to two decades larger than that possible with electrokinetic micropumps [12]. Due to the transmission of sound waves into the fluid through the undulating channel walls as the SAW traverses, it is also possible to switch between uniform through flow for fluid delivery, as shown in Fig. 4(a), and chaotic oscillatory flow for micromixing, as shown in Figs. 4(b)4(d) [11]. This can be achieved either by altering the microchannel width keeping the SAW excitation frequency constant, as shown in Fig. 4, or by changing the SAW frequency for a fixed width microchannel.

If, on the other hand, the fluid contained a suspension of colloidal particles and the input power is below the threshold required for fluid flow, the particles are observed to collect in a linear particle assembly along the nodes of the pressure field corresponding with the first order fluid motion arising due to the compressibility of the sound waves that are radiated into the fluid. The number of nodal lines and the number of aligned particle assemblies can be seen to correlate closely, as seen in Fig. 5. Such particle manipulation behavior can then be exploited for microchannel particle focusing [13].

\section{MICROCENTRIFUGATION}

It is possible to generate a microcentrifugatory flow by breaking the symmetry of the acoustic wave propagation across the substrate by a number of ways, as shown in Fig. 6 [14]. The 
A

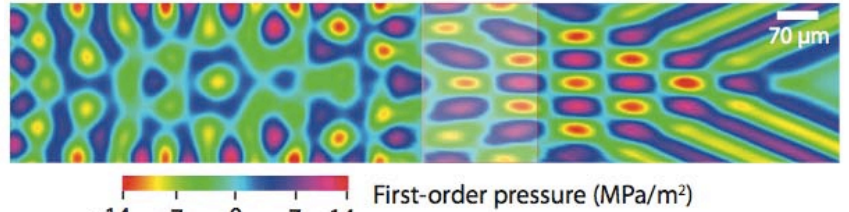

$\begin{array}{lllll}-14 & -7 & 0 & 7 & 14\end{array}$
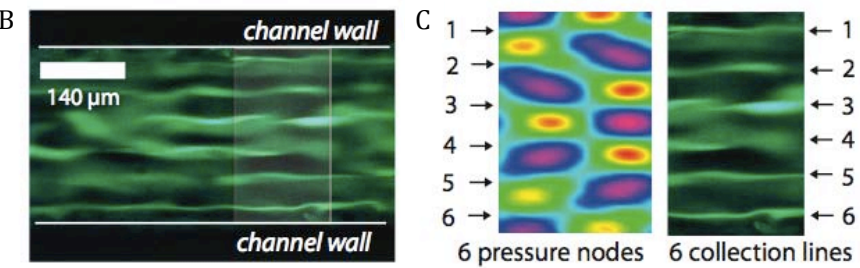

Figure 5. COMPARISON BETWEEN (A) THE COMPUTED FIRST ORDER PRESSURE FIELD IN THE FLUID AND (B) THE NUMBER OF LINEAR 500 NANOMETER COLLOIDAL PARTICLE ASSEMBLIES THAT ARISE IN THE QUIESCENT FLUID REGION. IT CAN BE SEEN IN (C) THAT THE PARTICLES APPEAR TO COLLECT ALONG THE NODES OF THE PRESSURE FIELD [11].

azimuthal fluid recirculation can be further intensified by focusing the SAW to a point underneath the drop with the use of the curved electric-width-controlled single-phase unidirectional transducer (SPUDT) electrodes shown in Fig. 7(A) in place of the conventional IDT design $[15,16]$. Unlike the conventional bidirectional IDT design shown schematically in Fig. 1(A), internally tuned reflectors within the IDT fingers in the SPUDT electrode design generates a unidirectional SAW that propagates from a single side of the IDT. The corresponding SAW pattern, which can be visualized through laser Doppler vibrometry or simply through smoke particle deposition patterns can be seen in Figs. 7(B) and 7(C), respectively. Azimuthal flows with linear velocities of around $1 \mathrm{~mm} / \mathrm{s}$ with the conventional IDTs and as high as $20 \mathrm{~mm} / \mathrm{s}$ with the focusing SPUDTs are observed, which can be exploited to drive intense micromixing. Shilton et al. [16] have shown that the chaoticlike inertial flow generated provides a means for driving effective turbulentlike mixing with an enhancement ratio $D_{\text {eff }} / D_{0}$ that scales roughly as the square of the input power to the IDT, where $D_{\text {eff }}$ is the effective diffusivity and $D_{0}$ is the diffusivity in the absence of flow. In [16], a small amount of food dye is shown to be completely mixed in a glycerine-water drop in under 1 second. Rapid particle concentration and separation can also be achieved through the microcentrifugation flow if the drop is suspended with microparticles or nanoparticles, as shown in Fig. 8, in which the particles are concentrated in under $1 \mathrm{~s}$, providing a convenient and effective means for pathogen preconcentration for fast and sensitive detection in biosensors or the separation of red blood cells from plasma in miniaturized point-of-care diagnostic kits.

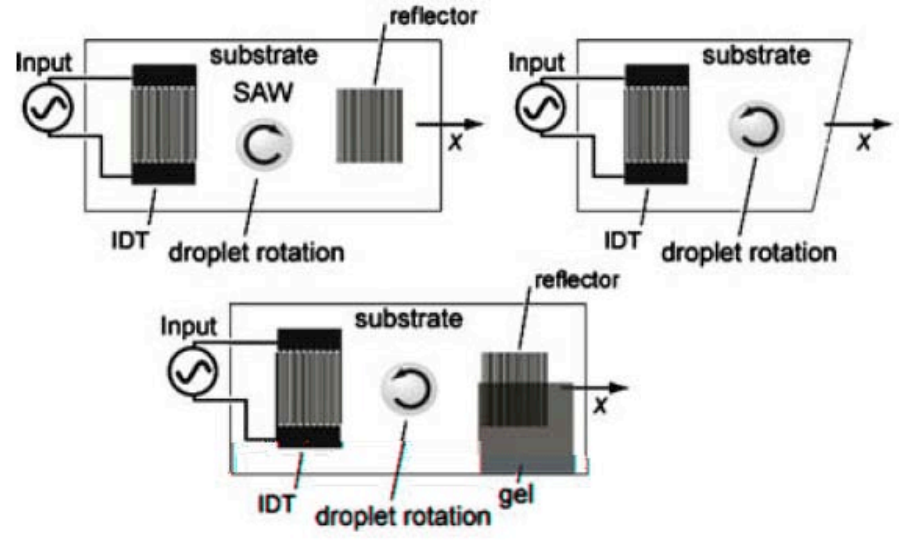

Figure 6. MICROCENTRIFUGATION FLOWS IN THE FORM OF AZIMUTHAL ACOUSTIC STREAMING WITHIN A DROP CAN BE GENERATED THROUGH SYMMETRY BREAKING OF THE SURFACE ACOUSTIC WAVE RADIATION PROPAGATION ACROSS THE SUBSTRATE EITHER BY PLACING THE DROP OFF-CENTER (TOP-LEFT), THROUGH ASYMMETRIC REFLECTION OF THE ACOUSTIC WAVE BY INTRODUCING A DIAGONAL CUT AT THE EDGE OF THE SUBSTRATE (TOP-RIGHT) OR THROUGH THE USE OF ABSORPTION GEL TO SUPPRESS THE REFLECTION AT ONE-HALF OF THE INTERDIGITAL TRANSDUCER ELECTRODE (BOTTOM) [14].

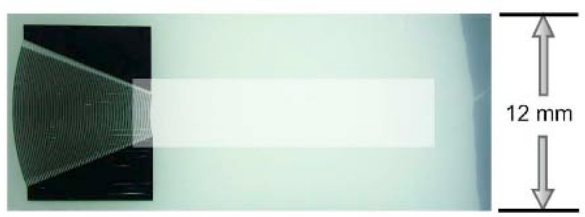

(A)

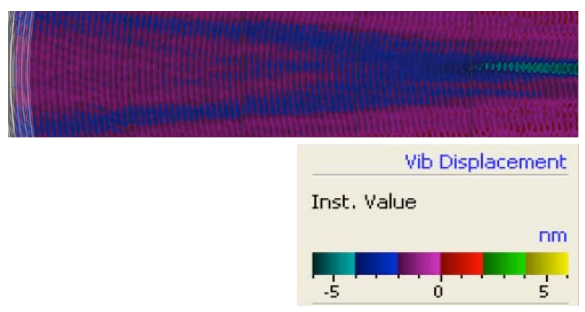

(B)

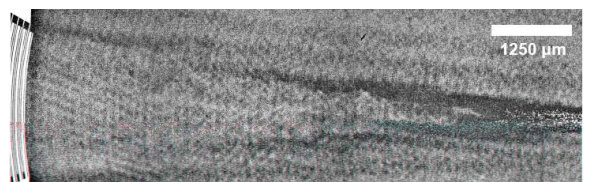

(C)

Figure 7. (A) FOCUSING ELLIPTICAL SINGLE-PHASE UNIDIRECTIONAL TRANSDUCER (SPUDT) ELECTRODE. THE CORRESPONDING SURFACE ACOUSTIC WAVE PATTERNS THAT ARE GENERATED, OBTAINED USING (B) LASER DOPPLER VIBROMETRY, AND, (C) SMOKE PARTICLE DEPOSITION, INDICATE THE INTENSIFICATION OF THE ACOUSTIC ENERGY TOWARDS A FOCAL POINT $[15,16]$. 

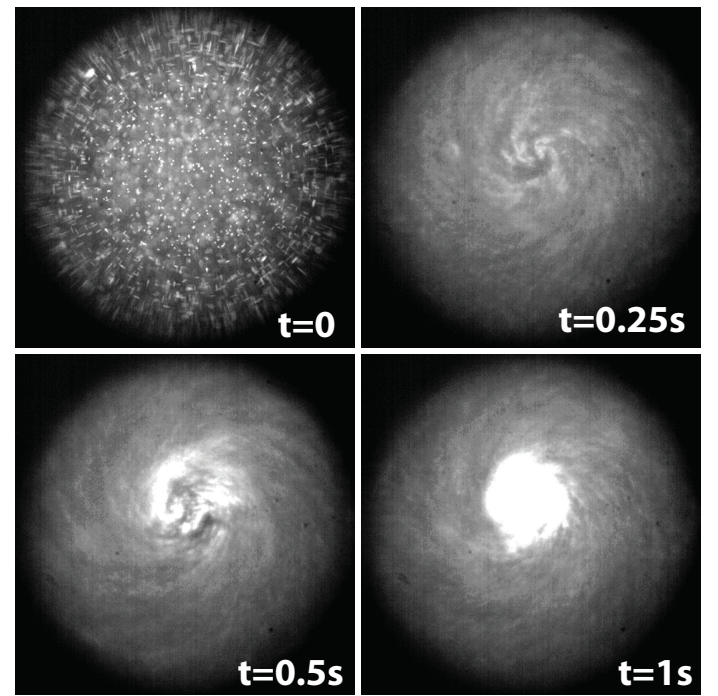

Figure 8. CONCENTRATION OF 500 NANOMETER FLUORESCENT PARTICLES IN A 0.5 MICROLITER WATER DROP DUE TO THE INERTIAL BULK FLUID RECIRCULATION THAT DRIVES A STRONG MICROCENTRIFUGATION EFFECT [16].
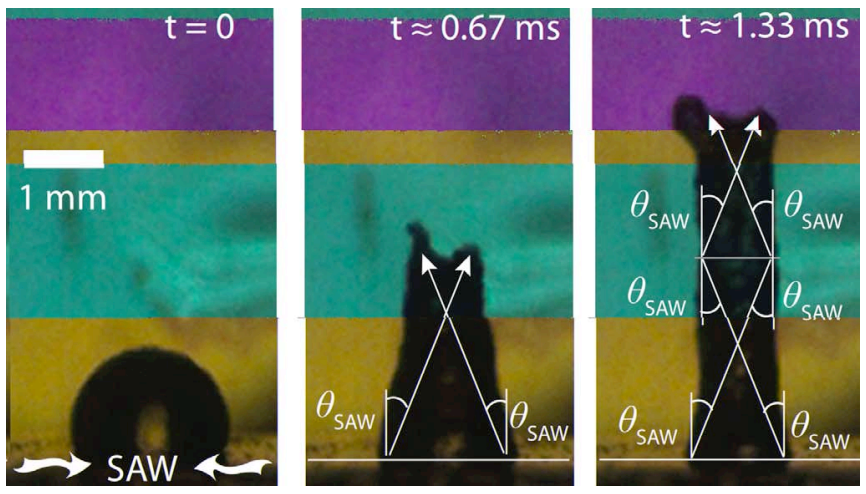

Figure 9. FORMATION OF AN ELONGATED JET BY CONCENTRATING THE ACOUSTIC RADIATION INTO THE DROP [17]

\section{JETTING \& ATOMIZATION}

Finally, if the input power and hence the SAW vibration amplitude is sufficiently large such that the capillary stresses holding the parent drop intact is overcome and significant interfacial deformation results. At these high powers, the substrate displacement velocity as the SAW traverses along the substrate surface is typically $1 \mathrm{~m} / \mathrm{s}$ irrespective of the excitation frequency. Given the SAW amplitude of approximately $10 \mathrm{~nm}$, large surface accelerations, on the order of 10 million $g$ 's can typically be generated, which in turn, drives the destabilization of the interface. If the SAW energy is concentrated to a point underneath the drop with the use of two elliptical focusing SPUDTs at two opposite ends, the transmission of radiation at the Rayleigh angle into the liquid from both the front and rear of the drop causes it to deform into

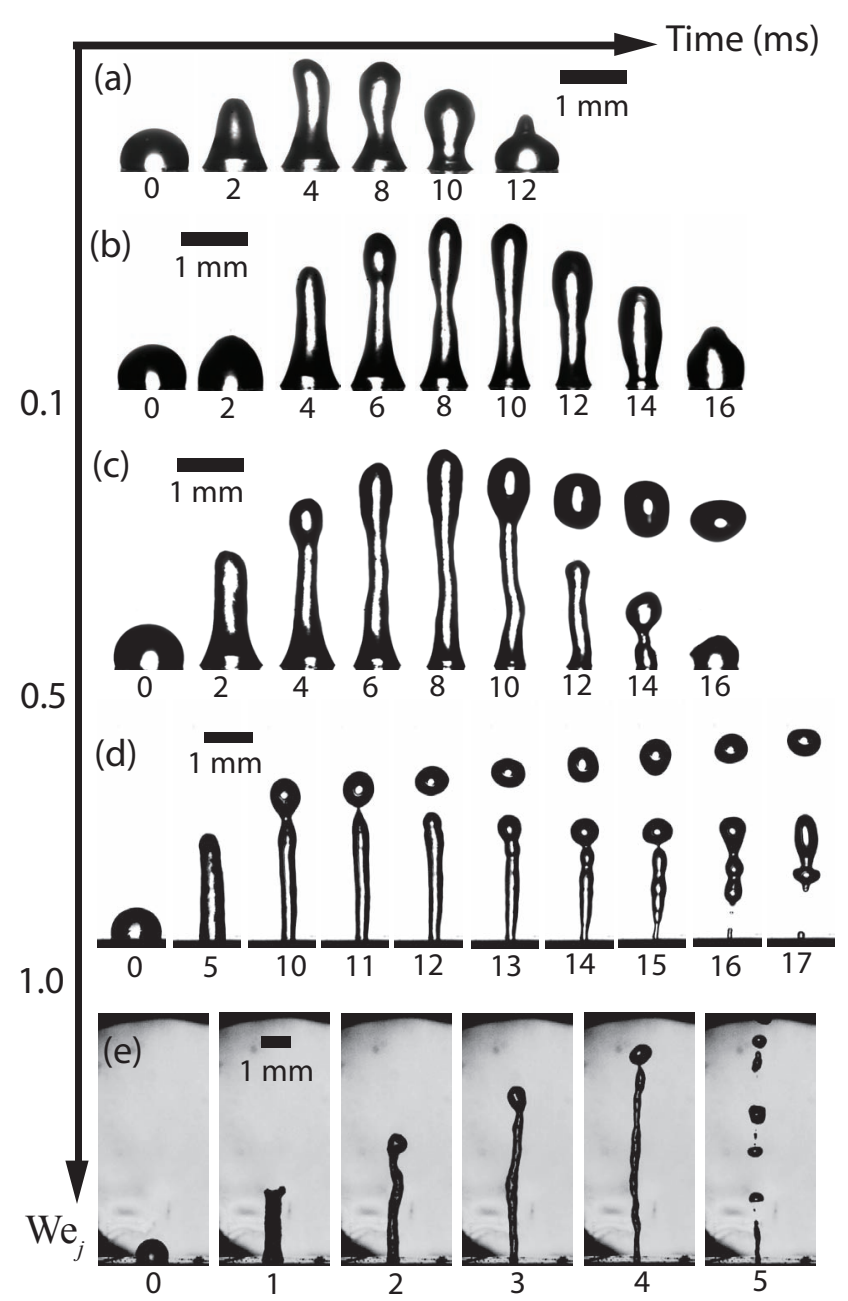

Figure 10. SURFACE ACOUSTIC WAVE JETTING AS A FUNCTION OF TIME, SHOWING THE DEPENDENCE OF ITS LENGTH AND BREAK-UP ON THE JET WEBER NUMBER We ${ }_{j}$ [17].

a coherent elongated liquid column, as shown in Fig. 9 [17]. It is therefore possible to generate a fluid jet that persists over centimeters in length from a millimeter dimension drop without requiring fluid confinement mechanisms such as nozzles or orifices to accelerate the fluid to adequately sufficient velocities requisite for producing an elongated jet. Not only does this demonstrate the ability for the SAW to drive strong inertial forcing on a liquid which is unique in microfluidic flows, the ability to induce such jets could have tremendous potential applications in inkjet or soft biological printing, fiber synthesis, and drug delivery, amongst others. Figure 10 shows the rich dynamics of the SAW jetting phenomenon, wherein we observe the jet length and the ability to generate single droplet or even multiple droplet ejection, to depend on the jet Weber number $\mathrm{We}_{j} \equiv \rho U_{j}^{2} R_{j} / \gamma$, where $\rho$ is the fluid density, $U_{j}$ the jet velocity, $R_{j}$ the jet radius and $\gamma$ the interfacial tension. 


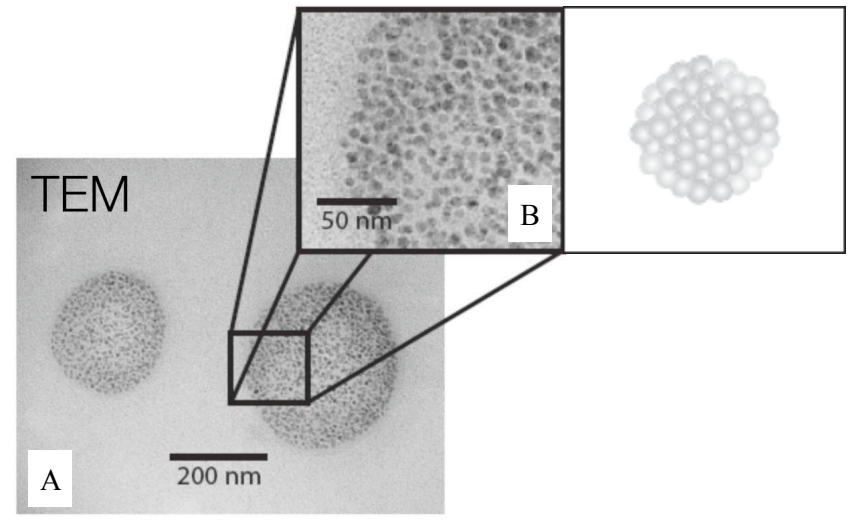

Figure 11. SYNTHESIS OF POLYMER NANOPARTICLES AROUND 150-200 NANOMETER IN DIAMETER WITH SURFACE ACOUSTIC WAVE ATOMIZATION. (A) TRANSMISSION ELECTRON MICROSCOPY (TEM) IMAGE OF A NANOPARTICLE. (B) MAGNIFICATION OF THE IMAGE SHOWING THE AGGREGATION OF SUB-50 NANOMETER PARTICULATES TO FORM A 200 NANOMETER CLUSTER, THE SCHEMATIC SHOWING A RECONSTRUCTION OF THE PARTICLE AGGREGATE [20].

If the power is not focused to a point underneath the drop or if the input power to the IDTs is increased further, the entire drop is completely destabilized and atomizes to produce a monodisperse distribution of aerosol droplets with a mean diameter of around 1-10 $\mu \mathrm{m}$ [18]. These monodispersed micron order droplets are particularly useful as drug-carrying vehicles for pulmonary drug delivery in which $2-5 \mu \mathrm{m}$ order aerosol drops are typically required for optimum dose efficiency in order to deliver the maximum amount of drug to the lower respiratory airways for direct local administration to target organs [19].The power required, typically $1 \mathrm{~W}$ or less, is at least a factor of ten smaller than that of ultrasonic atomizers which use Langevin transducers and single lead zirconium titanate element thickness-mode piston atomizers operating between $10 \mathrm{kHz}$ and $1 \mathrm{MHz}$. At these lower frequencies, drug molecules, DNA or proteins are susceptible to denaturing as cavitation becomes prevalent. Another advantage of the SAW atomization technique, as with the jetting phenomenon discussed above, is the ability to do away with nozzles and orifices which are prone to clogging, thus simplifying considerably the device and hence reducing its costs and increasing its reliability.

By atomizing a polymer solution, it is also possible to produce 150-200 nm spherical clusters of polymeric nanoparticles comprising sub-50 nm particulates, as shown in the schematic in Fig. 11 [20] . This one-step process for nanoparticle synthesis is therefore a straightforward, fast and attractive alternative to the multistep conventional methods for nanoparticle production such as spray drying, nanoprecipitation, emulsion photocross-linking, etc., which are slow and cumbersome. In addition, we have

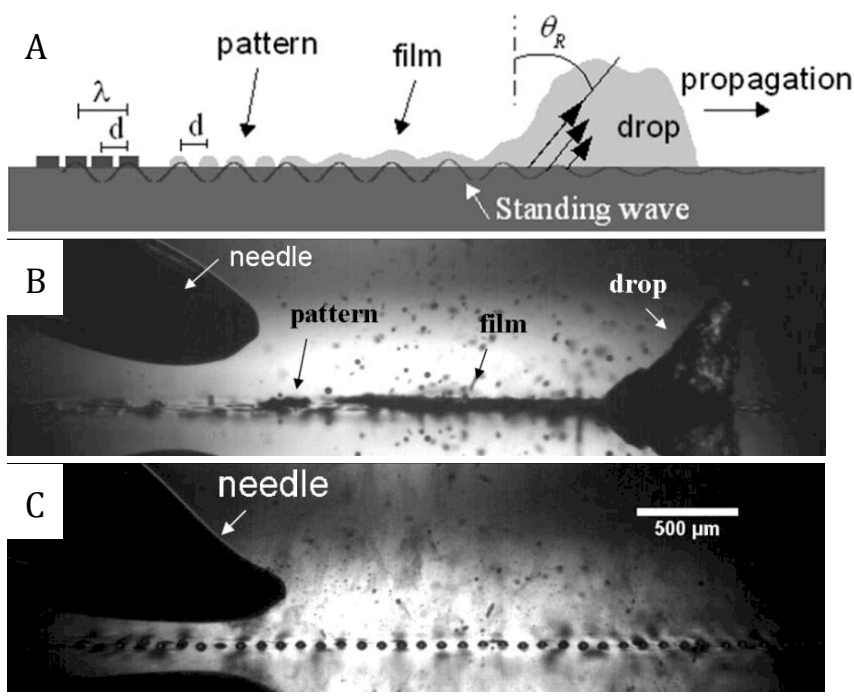

Figure 12. LONG-RANGE REGULAR POLYMER SPOT PATTERNING ARISING FROM THE ATOMIZATION OF A THIN FILM OF POLYMER SOLUTION DISPENSED FROM THE NEEDLE ABOVE THE SUBSTRATE (A,B). THE INITIAL DROP THAT IS DISPENSED TRANSLATES IN THE DIRECTION OF THE WAVE PROPAGATION, LEAVING BEHIND A THIN TRAILING FILM, WHICH SUBSEQUENTLY DESTABILIZES AND ATOMIZES, THUS LEAVING BEHIND (C) SOLIFIED POLYMER SPOTS AT THE ANTINODAL POSITIONS [23].

also demonstrated the possibility of generating $100 \mathrm{~nm}$ order dimension protein (insulin) nanoparticles as well as $3 \mu \mathrm{m}$ aerosol droplets for inhalation therapy [21]. Further, it is possible to load protein and other therapeutic molecules into the biodegradable polymer nanoparticle shells produced for controlled release drug delivery [22]. The encapsulation of the drug within the biodegradable polymer essentially shields the drug from rapid hydrolysis and degradation, permitting sustained release over time, and thus prolonging the effect of the drug over longer periods whilst preventing dangerous dose spikes. Our recent investigations have indicated the viability of primary mamalian osteoblast stem cells after SAW atomization thus suggesting that the technique can be used for drug loading without altering the nature of the biomolecule [9].

SAW atomization also offers the potential for the longrange, regular spatial-ordering of polymer spot patterns on a substrate without physical or chemical templating or other surface treatment procedures [23]. As shown in Figs. 12(a) and 12(b), the translation of a drop containing the polymer solution leaves behind a thin trailing film, which simultaneously destabilizes, thus thinning the film at the antinodes of the standing SAW vibration and resulting in its depletion of the film there. The breakup of the film across the entire substrate surface at these positions and the subsequent evaporation of the solvent 

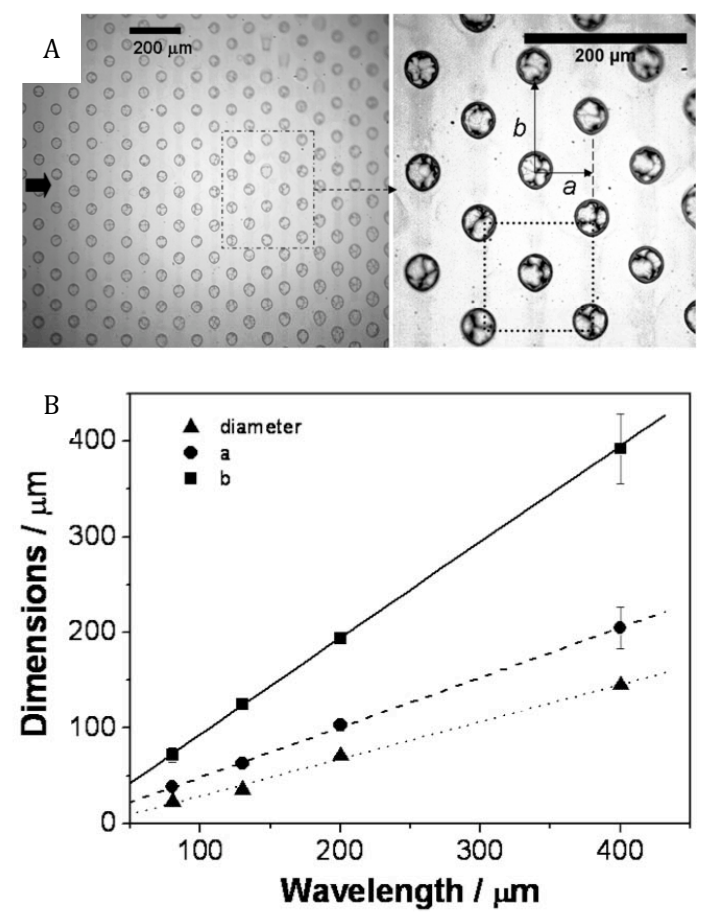

Figure 13. (A) THE REGULAR ARRAY OF POLYMER SPOTS PRODUCED . (B) THE SPOT DIAMETER, LONGITUDINAL PITCH SPACING $A$ AND TRANSVERSE PITCH SPACING $B$ ARE OBSERVED TO BE STRONGLY CORRELATED WITH THE FREQUENCY AND WAVELENGTH OF THE SURFACE ACOUSTIC WAVE [23].

then yields the evenly spaced solidified polymer droplet patterns shown in Figs. 12(c) and 13(a). The pattern periodicity as well as the polymer spot size is observed to strongly correlate with the SAW frequency or wavelength, as shown in Fig. 13(b), therefore presenting the ability for control and fine tuning, which is a key advantage over other conventional patterning methods [23].

\section{ACKNOWLEDGMENT}

This work would not have been possible without close collaboration with J. Friend and the talented students and postdocs who have shared in our journey on SAW microfluidics and whose work has led to the discoveries described above. They are, in alpabetical order, M. Alvarez, D. Arifin, K. Kulkarni, H. Li, A. Qi, R. Shilton, R. Raghavan and M. K. Tan. In addition, we would also like to thank our collaborators A. Dasvarma (Australian Stem Cell Centre), M. McIntosh (Monash University), A. Mechler (LaTrobe University), D. Morton (Monash University), P. Perlmutter (Monash University), L. Spiccia (Monash University) and K. Traianedes (Australian Stem Cell Centre). We also acknowledge funding from the Australian Research Council (Discovery Projects DP0666549, DP0666660, \& DP098525; Linkage, Infrastructure, Equipment \& Facilities LP0668435),
Nanotechnology Victoria, and the Research Support for CounterTerrorism programme administered by the Department of Prime Minister \& Cabinet's Office of National Security.

\section{REFERENCES}

[1] Yeo, L. Y. and Friend, J. R., 2009. "Ultrafast Microfluidics Using Surface Acoustic Waves". Biomicrofluidics, 3, 012002.

[2] Li, H., Friend, J. R., and Yeo, L. Y., 2008. "Microfluidic Colloidal Island Formation and Erasure Induced by Surface Acoustic Wave Radiation". Physical Review Letters, 101, 084502.

[3] Renaudin, A., Tabourier, P., Zhang, V., Camart, J. C., and Druon, C., 2006. "SAW Nanopump for Handling Droplets in View of Biological Applications". Sensors and Actuators $B$, 133, pp. 389-397.

[4] Tan, M. K., Friend, J. R., and Yeo, L. Y., 2007. "Microparticle Collection and Concentration Via a Miniature Surface Acoustic Wave Device". Lab on a Chip, 7, pp. 618-625.

[5] Yeo, L. Y. and Chang, H.-C., 2005. "Static and Spontaneous Electrowetting”. Modern Physics Letters B, 19, pp. 549569.

[6] Guttenberg, Z., Müller, H., Habermüller, H., Geisbauer, A., Pipper, J., Falbel, J., Kielpinski, M., Scriba, J., and Wixforth, A., 2005. "Planar Chip Device for PCR and Hybridization with Surface Acoustic Wave Pump". Lab on a Chip, 5, pp. 308-317.

[7] Li, H., Friend, J. R., and Yeo, L. Y., 2007. "A Scaffold Cell Seeding Method Driven by Surface Acoustic Waves". Biomaterials, 28, pp. 4098-4104.

[8] Bok, M., Li, H., Yeo, L. Y., and Friend, J. R., 2009. "The Dynamics of Surface Acoustic Wave-Driven Scaffold Cell Seeding". Biotechnology and Bioengineering, 103, pp. 387-401.

[9] Li, H., Friend, J., Yeo, L., Dasvarma, A., and Traianedes, K., 2009. "Effect of Surface Acoustic Waves on the Viability, Proliferation and Differentiation of Primary Osteoblastlike Cells", Biomicrofluidics, 3, 034102.

[10] Girardo, S., Cecchini, M., Beltram, F., Cingolani, R., and Pisignano, D., 2008. "Polydimethylsiloxane- $\mathrm{LiNbO}_{3}$ Surface Acoustic Wave Micropump Devices for Fluid Control Into Microchannels". Lab on a Chip, 8, pp. 1557-1563.

[11] Tan, M. K., Yeo, L. Y., and Friend, J. R., 2009. "Rapid Fluid Flow and Mixing Induced in Microchannels Using Surface Acoustic Waves". Europhysics Letters, to appear.

[12] Laser, D. J. and Santiago, J. G. , 2004. "A Review of Micropumps". Journal of Micromechanics and Microengineering, 14, pp. R35-R64.

[13] Shi, J., Mao, X., Ahmed, D., Colletti, A., and Huang, T. J., 2008. "Focusing Microparticles in a Microfluidic Channel 
With Standing Surface Acoustic Waves (SSAW)". Lab on a Chip, 8, pp. 221-223.

[14] Li, H., Friend, J. R., and Yeo, L. Y., 2007. "Surface Acoustic Wave Concentration of Particle and Bioparticle Suspensions". Biomedical Microdevices 9, pp. 647-656.

[15] Tan, M. K., Friend, J. R., and Yeo, L. Y., 2007. "Direct Visualization of Surface Acoustic Waves Along Substrates Using Smoke Particles". Applied Physics Letters, 91, 224101.

[16] Shilton, R., Tan, M. K., Yeo, L. Y., and Friend, J. R., 2008. "Particle Concentration and Mixing in Microdrops Driven by Focused Surface Acoustic Waves". Journal Applied Physics, 104, 014910.

[17] Tan, M. K., Friend, J. R., and Yeo, L. Y., 2009. "Interfacial Jetting Phenomena Induced by Focused Surface Vibrations". Physical Review Letters, 103, 024501.

[18] Qi, A., Yeo, L. Y., and Friend, J. R., 2008. "Interfacial Destabilization and Atomization Driven by Surface Acoustic Waves". Physics of Fluids, 20, 074103.

[19] Qi, A., Friend, J. R., Yeo, L. Y., Morton, D. A. V., McIntosh, M. P., and Spiccia, L., 2009. "Miniature Inhalation Therapy Platform Using Surface Acoustic Wave Microfluidic Atomization”. Lab on a Chip, 9, pp. 2184-2193.

[20] Friend, J. R., Yeo, L. Y., Arifin, D. R., and Mechler, A., 2008. "Evaporative Self-Assembly Assisted Synthesis of Polymeric Nanoparticles By Surface Acoustic Wave Atomization". Nanotechnology, 19, 145301.

[21] Alvarez, M., Friend, J. R., and Yeo, L. Y., 2008. "Rapid Generation of Protein Aerosols and Nanoparticles Via Surface Acoustic Wave Atomization". Nanotechnology, 19, 455103.

[22] Alvarez, M., Yeo, L. Y., and Friend, J. R., 2009. "Rapid Production of Protein-Loaded Biodegradable Microparticles Using Surface Acoustic Waves". Biomicrofluidics, 3, 014102.

[23] Alvarez, M., Friend, J. R., and Yeo, L. Y., "Surface Vibration Induced Spatial Ordering of Periodic Polymer Patterns on a Substrate". Langmuir, 24, pp. 10629-10632. 